\title{
Integration of "what" and "where" in frontal cortex during visual imagery of scenes
}

Citation for published version (APA):

de Borst, A. W., Sack, A. T., Jansma, B. M., Esposito, F., de Martino, F., Valente, G., Roebroeck, A., Di Salle, F., Goebel, R., \& Formisano, E. (2012). Integration of "what" and "where" in frontal cortex during visual imagery of scenes. Neuroimage, $60(1), 47-58$. https://doi.org/10.1016/j.neuroimage.2011.12.005

Document status and date:

Published: 01/03/2012

DOI:

10.1016/j.neuroimage.2011.12.005

Document Version:

Publisher's PDF, also known as Version of record

Document license:

Taverne

Please check the document version of this publication:

- A submitted manuscript is the version of the article upon submission and before peer-review. There can be important differences between the submitted version and the official published version of record.

People interested in the research are advised to contact the author for the final version of the publication, or visit the DOI to the publisher's website.

- The final author version and the galley proof are versions of the publication after peer review.

- The final published version features the final layout of the paper including the volume, issue and page numbers.

Link to publication

\footnotetext{
General rights rights.

- You may freely distribute the URL identifying the publication in the public portal. please follow below link for the End User Agreement:

www.umlib.nl/taverne-license

Take down policy

If you believe that this document breaches copyright please contact us at:

repository@maastrichtuniversity.nl

providing details and we will investigate your claim.
}

Copyright and moral rights for the publications made accessible in the public portal are retained by the authors and/or other copyright owners and it is a condition of accessing publications that users recognise and abide by the legal requirements associated with these

- Users may download and print one copy of any publication from the public portal for the purpose of private study or research.

- You may not further distribute the material or use it for any profit-making activity or commercial gain

If the publication is distributed under the terms of Article $25 \mathrm{fa}$ of the Dutch Copyright Act, indicated by the "Taverne" license above, 


\title{
Integration of "what" and "where" in frontal cortex during visual imagery of scenes
}

\author{
Aline W. de Borst ${ }^{\mathrm{a}, \mathrm{b}, *}$, Alexander T. Sack ${ }^{\mathrm{a}}$, Bernadette M. Jansma ${ }^{\mathrm{a}}$, Fabrizio Esposito ${ }^{\mathrm{a}, \mathrm{c}}$, \\ Federico de Martino a, Giancarlo Valente ${ }^{\mathrm{a}}$, Alard Roebroeck ${ }^{\mathrm{a}}$, Francesco di Salle ${ }^{\mathrm{a}, \mathrm{b}}$, \\ Rainer Goebel ${ }^{\mathrm{a}, \mathrm{d}}$, Elia Formisano ${ }^{\mathrm{a}}$ \\ a Department of Cognitive Neuroscience, Faculty of Psychology and Neuroscience, Maastricht University, Maastricht, The Netherlands \\ b Department of Neuroscience, University of Pisa, Pisa, Italy \\ c Department of Neuroscience, University of Naples Federico II, Naples, Italy

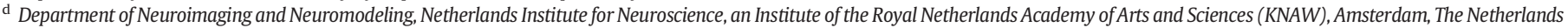

\section{A R T I C L E I N F O}

\section{Article history:}

Received 11 July 2011

Revised 1 December 2011

Accepted 2 December 2011

Available online 13 December 2011

\section{Keywords:}

fMRI

EEG

Mental imagery

Scenes

Frontal cortex

\begin{abstract}
A B S T R A C T
Imagination is a key function for many human activities, such as reminiscing, learning, or planning. Unravelling its neuro-biological basis is paramount to grasp the essence of our thoughts. Previous neuroimaging studies have identified brain regions subserving the visualisation of "what?" (e.g. faces or objects) and "where?" (e.g. spatial layout) content of mental images. However, the functional role of a common set of involved regions - the frontal regions - and their interplay with the "what" and "where" regions, has remained largely unspecified. This study combines functional MRI and electroencephalography to examine the fullbrain network that underlies the visual imagery of complex scenes and to investigate the spectro-temporal properties of its nodes, especially of the frontal cortex.

Our results indicate that frontal regions integrate the "what" and "where" content of our thoughts into one visually imagined scene. We link early synchronisation of anterior theta and beta oscillations to regional activation of right and central frontal cortices, reflecting retrieval and integration of information. These frontal regions orchestrate remote occipital-temporal regions (including calcarine sulcus and parahippocampal gyrus) that encode the detailed representations of the objects, and parietal "where" regions that encode the spatial layout into forming one coherent mental picture. Specifically the mesial superior frontal gyrus appears to have a principal integrative role, as its activity during the visualisation of the scene predicts subsequent performance on the imagery task.
\end{abstract}

(c) 2011 Elsevier Inc. All rights reserved.

\section{Introduction}

Though often unconsciously, we commonly use mental representations of objects, events and even complex scenes that are not physically present in many of our everyday-life activities. This phenomenon of mental imagination refers to the set of cognitive processes that allows the generation, inspection, and manipulation of such mental representations, and it is likely the cognitive ability at the heart of several core cognitive functions such as object recognition (Riesenhuber and Poggio, 2000), spatial orientation (Goldstein, 2002), learning (Kosslyn et al., 1995), and memory (Cohen et al., 1996).

The neuro-biological mechanism underlying mental imagery is a complex system with a multitude of nodes and interaction-patterns in the brain. Numerous neuropsychological (Farah et al., 1988; Levine et al., 1985) and, more recently, neuroimaging studies

\footnotetext{
* Corresponding author at: Department of Cognitive Neuroscience, Faculty of Psychology and Neuroscience, Maastricht University, Universiteitssingel 40, 6229 ER, Maastricht, The Netherlands. Fax: + 31433884125.

E-mail address: aline.deborst@maastrichtuniversity.nl (A.W. de Borst).
}

(Cohen et al., 1996; D'Esposito et al., 1997; Knauff et al., 2000; Mellet et al., 1998; Mellet et al., 1996; Richter et al., 1997; Trojano et al., 2000) have aimed at unravelling the neural foundations of mental imagery using a wide variety of tasks (for a review, see Kosslyn et al., 2001). However, all of these previous imaging studies focused on only a certain subset of these imagery-related brain regions, using tasks that explored a particular aspect of mental imagery. These studies have shown that analogous to the distinction between the ventral "what" and the dorsal "where" cortical processing streams in visual perception (Ungerleider and Haxby, 1994), a dichotomy exists between the imagination of objects or scenes versus the imagination of spatial features and relationships. In line with this distinction, some studies focussed on examining the visual imagery of objects and subsequently reported imagery-related activity in category-specific occipital-temporal regions as a main finding (Ishai et al., 2002; Ishai et al., 2000; O'Craven and Kanwisher, 2000). In a separate research line, other brain imaging studies revealed the involvement of brain regions within the dorsal pathway during imagery tasks that included a spatial processing component, suggesting that the fronto-parietal networks activated during perceptual visuospatial tasks also underlie the spatial analysis of mentally imagined representations (Cohen 
et al., 1996; Lamm et al., 2001; Mellet et al., 1996; Tagaris et al., 1996; Trojano et al., 2000). In addition to these task-specific imagery regions within temporal and parietal cortex, both research lines also descriptively reported activation of a set of frontal regions common to all mental imagery tasks. However, while the ventral stream regions were suggested to contribute to the retrieval of content-specific object representations from memory (Ishai et al., 2000), and a functional segregation for spatial image construction and inspection was proposed between left and right posterior parietal cortex (Formisano et al., 2002; Sack et al., 2005; Sack et al., 2002), a systematic investigation of the precise functional role of these frontal regions and their relationship to the task-specific network nodes during mental imagery has been neglected. All previous neuroimaging mental imagery studies, including our own work, have restricted their analyses to the functional localization of a small number of regions, leading to a simplification of the intricate network dynamics during mental imagery.

In this study, we examine the spatio-temporal dynamics of activity in frontal regions and their relation to parietal, occipital-temporal, and primary sensory brain regions, during a behaviourally-controlled task that captures both object and spatial mental imagery. Participants were asked to imagine a previously learned complex visual scene from an auditory cue and, after a certain delay, had to judge whether a visually presented fragment of the scene was mirrored or not. We used event-related functional MRI (fMRI) and latency analysis techniques on the imagery period to capture all imagery-relevant network nodes and their relative temporal onset of activation. In addition, we performed the same scene imagery task during electroencephalography (EEG) measurements to validate our fMRI latency results and to derive more information on the specific functional role of the brain regions from the involved frequency bands. For example, the involvement of the alpha rhythm is often associated with global cognitive engagement (Barrett and Ehrlichman, 1982; Bhattacharya and Petsche, 2005; Gill et al., 1998; Marks and Isaac, 1995; Nikolaev and Anokhin, 1998; Petsche et al., 1997; Petsche et al., 1992), whereas the involvement of the theta or beta rhythm could point to a more specific function such as, respectively, working memory (Bhattacharya and Petsche, 2005; Petsche et al., 1997; Rugg and Venables, 1980) or the integration of information into a rehearsal set (Onton et al., 2005). Our experimental design and methodological approach enabled us to link the spatially-resolved information on the distributed brain network underlying the mental imagery of complex scenes as revealed by fMRI, with the spectral-temporal electrophysiological dynamics within this same network using EEG. We aimed at deriving an exhaustive functional neuro-anatomical model of mental imagery, in which the specific integrative role of the frontal regions and their interplay with the parietal, temporal, and sensory brain regions during complex visual scene imagery is clarified.

\section{Material and methods}

\section{Participants}

Ten healthy right-handed volunteers ( 8 females, 2 males, mean age 22.2 years; range 18-26) participated in the fMRI study. Seven healthy right-handed volunteers (3 females, 4 males, mean age 24.3 years; range $21-29$ ), which did not take part in the fMRI experiment, participated in the EEG study. All participants had normal or corrected-to-normal vision and gave their informed consent. The studies were approved by the local ethical committee.

\section{Stimuli and task}

Twenty-seven digital colour photographs were used as stimuli (1024 by 768 pixels). Three photographs (see example in Fig. 1) depicted the interior of a room and comprised several pieces of furniture. These photographs defined the visual imagery content and were solely used during a training phase. Twelve photographs (targets) were fragments of the three original scenes (four per scene), containing a minimum of two partly visible objects. The other twelve photographs (targets) were these same images mirrored across the horizontal axis (see Fig. 1). The default image was a grey background ( $50 \%$ black, $50 \%$ white). All photographs contained a central white fixation cross and were presented at a $24^{\circ}$ by $30^{\circ}$ visual angle (fMRI) or at $5^{\circ}$ by $7^{\circ}$ visual angle (EEG).

The experiment consisted of 54 ( 3 associations $\times 18$ repetitions) trials (two runs of 27 trials each) in fMRI and $216(3 \times 72)$ trials in EEG ( 3 runs of 72 trials each). As depicted in Fig. 1, each trial of the fMRI and EEG experiments started with an auditory cue. In the fMRI study, three auditory stimuli were 1 second (s) sound clips of a female speaker uttering "photo one", "photo two" or "photo three". In the EEG study, the three auditory stimuli were $400 \mathrm{~ms}$ tones at 800 , 1000 and $1200 \mathrm{~Hz}$ (due to similarity in EEG patterns). During the subsequent interval participants imagined the scene that they previously had learned to associate with the cue. After a variable delay (fMRI: 5 , 6 , or $7 \mathrm{~s}$, average $=6 \mathrm{~s}$, EEG: $5,5.5$, or $6 \mathrm{~s}$, average $=5.5 \mathrm{~s}$ ) a mirrored or non-mirrored fragment of the scene ( $50-50 \%$ distribution) was visually presented as a target. After each target participants pressed a button with their right middle or index finger to indicate whether the fragment matched the imagined scene, or was mirrored (reversed in half of the participants). All trials ended with a fixation period (fMRI: 8-12 s, EEG: 4-5 s) during which the participants performed no task. The interval lengths were pseudo-randomised over trials and the occurrence of each period length was equally distributed over the three types of trials (scene one, two and three) and type of target picture (mirrored or non-mirrored). The trials were pseudorandomised with respect to the order of the tones and target pictures.

Prior to fMRI measurements and the EEG main experiment, participants were trained on imagining three scenes, associated with three auditory cues. The training session consisted of 24 randomised trials of simultaneous presentation of the auditory stimulus and the corresponding visual scene ( $5 \mathrm{~s}$ ), followed by a fixation period ( $6 \mathrm{~s})$. After each stimulus pair was repeated eight times, subjects were asked whether they correctly remembered which tone belonged to which scene and were able to recall all scenes vividly. All participants indicated that they were able to do so. After training, participants received task instructions and were asked to vividly visualise the correct scene after each cue in the main experiment, while fixating at the fixation cross. The EEG measurements during training were omitted from further analyses.

The EEG training session and the EEG main experiment were preceded by an auditory control task. During this task participants were presented with a total of 216 randomised trials of three auditory stimuli, to which they listened passively. Each trial consisted of a $400 \mathrm{~ms}$ tone and a fixation period (random interval between 6 and $7 \mathrm{~s}$ ). These same tones were used as cues in the training session and the main experiment.

\section{Data acquisition}

\section{Functional imaging data acquisition}

A $3 T$ Siemens MR (head) scanner (MAGNETOM Allegra, Siemens Medical Systems, Erlangen, Germany) was used for imaging. Functional scans were acquired with a Gradient Echo Echo-Planar Imaging sequence with a Repetition Time (TR) of $1500 \mathrm{~ms}$ and an Echo Time (TE) of $30 \mathrm{~ms}$. For each functional run 370 volumes were acquired comprising 23 slices (matrix $=64 \times 64$, voxel dimensions $=$ $3 \times 3 \times 4.5 \mathrm{~mm}^{3}$, interslice time $=65 \mathrm{~ms}$, flip angle $=90^{\circ}$ ). Between the two functional runs high resolution T1-weighted structural images of the whole brain were acquired ( 3 subjects: MPRAGE 192 slices, matrix $=256 \times 256$, voxel dimensions $=1 \times 1 \times 1 \mathrm{~mm}^{3}$, $\mathrm{TR}=2300 \mathrm{~ms}, \mathrm{TE}=3.93 \mathrm{~ms}$, flip angle $=12^{\circ} ; 7$ subjects: MDEFT 


\begin{tabular}{|c|c|c|c|c|c|}
\hline Training & Study & $\begin{array}{c}\text { Cue } \\
\text { duration }\end{array}$ & $\begin{array}{c}\text { Imagery } \\
\text { duration (avg) }\end{array}$ & $\begin{array}{c}\text { Target } \\
\text { duration }\end{array}$ & $\begin{array}{c}\text { Fixation } \\
\text { duration (avg) }\end{array}$ \\
\hline $\begin{array}{c}\text { Scenes } \\
+ \\
\text { cues }\end{array}$ & fMRI & $1000 \mathrm{~ms}$ & $6000 \mathrm{~ms}$ & $2500 \mathrm{~ms}$ & $10000 \mathrm{~ms}$ \\
\hline
\end{tabular}
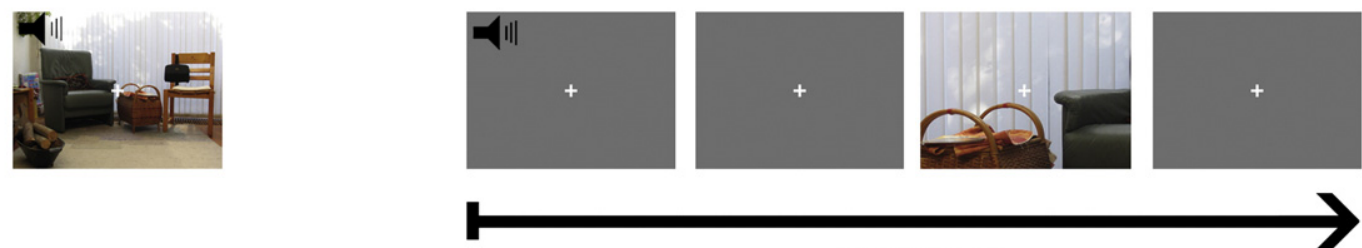

Trial Time

Fig. 1. Schematic overview of the temporal course of one exemplary trial in the fMRI and EEG experiment. The duration of each segment is indicated in milliseconds.

176 slices, matrix $=256 \times 256$, voxel dimensions $=1 \times 1 \times 1 \mathrm{~mm}^{3}$, $\mathrm{TR}=7.92 \mathrm{~ms}, \mathrm{TE}=2.40 \mathrm{~ms}$, flip angle $=15^{\circ}$ ).

\section{Electroencephalography data acquisition}

The EEG data were recorded in a sound-attenuating and electrically shielded room from 64 electrode sites (EasyCap system, Equidistant 61Channel Arrangement cap). One electrode was placed under the left eye to measure eye movements. The reference was placed at the left mastoid. The ground electrode was fixated at the right cheek. Impedance was kept below $5 \mathrm{k} \Omega$. A chin rest was used to minimise head motion and to keep the head at a constant distance from the PC screen in order to maintain the correct visual angle. The data were sampled at $500 \mathrm{~Hz}$, with a band-pass filter of $0.01-100 \mathrm{~Hz}$.

\section{Data analyses}

\section{Functional MRI pre-processing and data analyses}

All functional MRI data were analysed using fMRI analysis and visualisation software BrainVoyager QX (Brain Innovation B.V., Maastricht, The Netherlands). Functional data were 3D motion corrected (trilinear interpolation), corrected for slice scan time differences and temporally filtered (high pass: 5 cycles/run cut-off). No spatial filtering was applied in order not to contaminate localization of e.g. sub-cortical structures. The anatomical data were corrected for intensity inhomogeneity (Goebel et al., 2006) and transformed into Talairach space (Talairach and Tournoux, 1988). The functional data were then aligned with the anatomical data and transformed into the same space, to create $4 \mathrm{D}$ volume time-courses (VTCs). The anatomical data were used for surface reconstruction of both hemispheres in all subjects (description of cortex segmentation in Goebel et al., 2006). Statistical modelling of the time-courses was based on a deconvolution analysis (Dale and Buckner, 1997; Lu et al., 2006; Lu et al., 2007; Ward, 1998). As described in Serences (2004), we created for each subject - a design matrix X with separate columns for each time point along the expected event-related BOLD response to each mental imagery trial. A ' 1 ' ('stick predictor') was placed in each row of the design matrix in the column corresponding to the point along the BOLD response to be estimated. To cover the typical temporal extend of the hemodynamic response, we used 13 separate stick predictors during a $19.5 \mathrm{~s}$ window $(\mathrm{TR}=1.5 \mathrm{~s})$ after trial onset. The beta weights corresponding to these predictors are thus estimates of the hemodynamic response amplitude at each TR and therefore their plot is a representation of the estimated BOLD response (Fig. 3A). A group design matrix was created based on the concatenation of single-subject deconvolution matrices (fixed effect GLM). After GLM fitting (which estimates a beta for each stick predictor), the group map depicting the spatio-temporal pattern of Blood-Oxygen-Level Dependent (BOLD) activation of the 'imagery' period (Fig. 2) was calculated by contrasting the first five predictors versus baseline. This map was thresholded at a Bonferroni corrected $p<0.05$. To visualise information about BOLD latency, we colour coded significantly active voxels according to the earliest stick predictor for which the beta weight was significantly greater than baseline (i.e. a dark green colour indicates a significant beta weight for the stick predictor corresponding to the first TR after sound onset, a lighter green to second TR, etc.).

In order to quantify the BOLD latency with sub-TR resolution, a non-linear analytical procedure (Richter et al., 2000) was applied to BOLD response data in the selected regions of interest (ROIs). For each ROI, a time-course was obtained by spatially averaging the voxel time-courses and was then temporally interpolated by a factor of 3. Then, a piece-wise linear (PWL) fitting (pseudo-trapezoid) procedure with four break-points was applied to the resulting timecourses. The non-linear model, consisting of a series of lines, is fitted to the response in such a way that the same shape is parsimoniously described in terms of a few aspects: onset, plateau and offset - independent of response amplitude. We used this non-linear fit to identify the first break point, i.e. the point at which the BOLD response starts, for each ROI (see Fig. 3B) (Formisano and Goebel, 2003; Formisano et al., 2002; Linden et al., 2011). In the PWL fitting procedure the initial and final baseline levels were not constrained to be identical since the epochs were cut off before target onset (i.e. no return to initial baseline was forced in the PWL fit before the end of the time window of interest).

\section{Reaction time based fMRI analyses}

For each participant, reaction times (onset time button-press minus onset time target) of the correct trials were calculated. Trials were ordered according to response latencies and a median split was applied, resulting in a group of "fast" and "slow" trials per participant. Functional MRI trials were labelled based on these two categories and compared. An estimate of the hemodynamic response at each imagery and target picture interval for the fast and slow conditions was obtained using a boxcar predictor convolved with a hemodynamic response function. A fixed effect GLM was performed with a contrast testing for a difference in BOLD signal during the imagery 


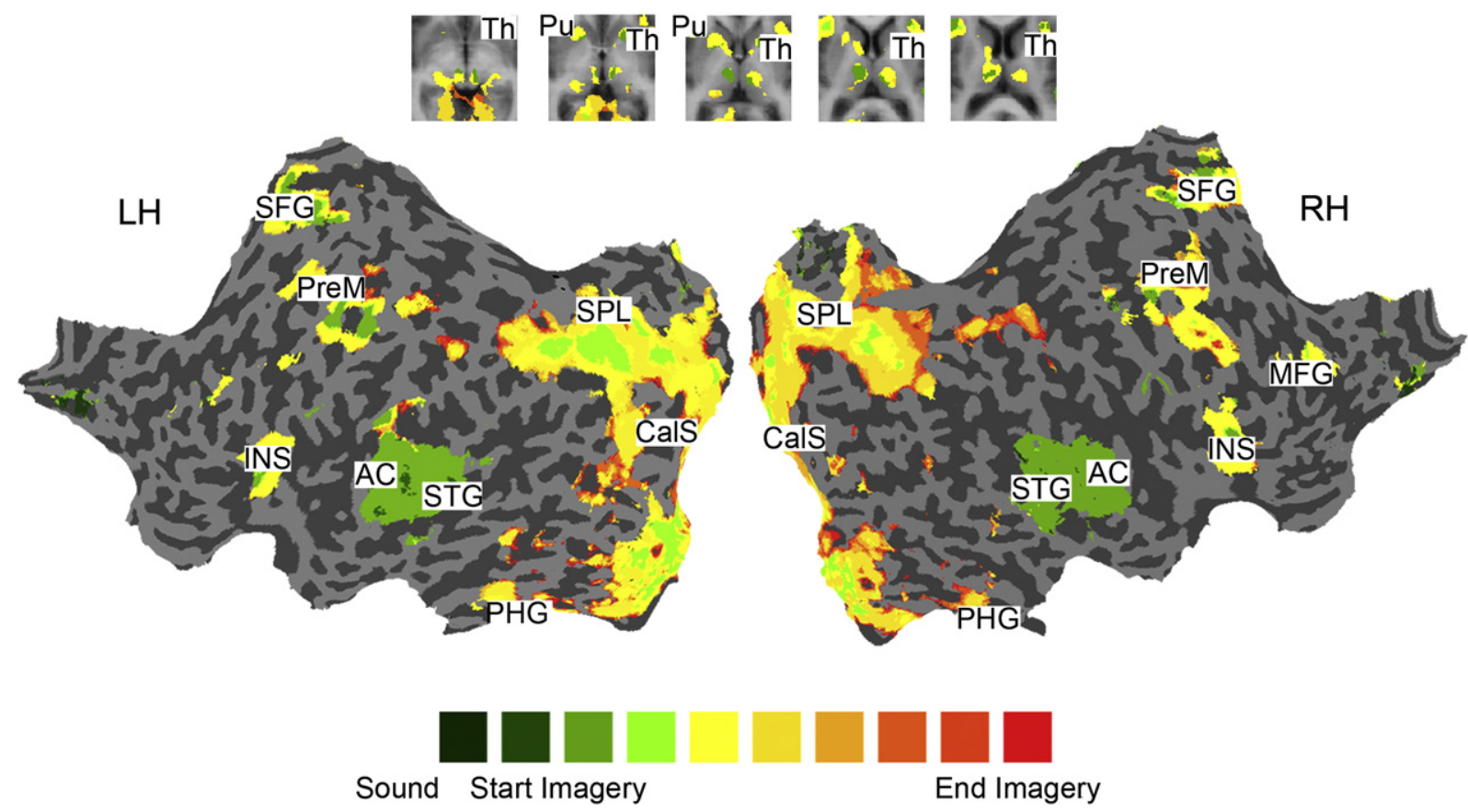

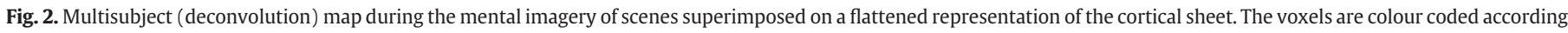

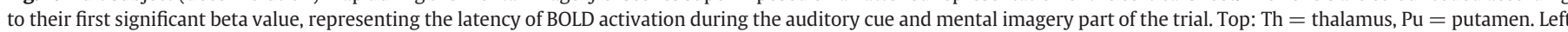

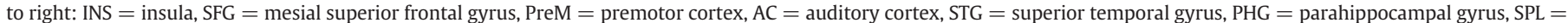
superior parietal lobule, CalS $=$ calcarine sulcus, MFG = middle frontal gyrus

periods followed by fast or slow responses, thresholded using a False Discovery Rate (FDR) of 0.05 (Genovese et al., 2002).

\section{Electroencephalography pre-processing and data analyses}

EEGLAB, an open source Matlab toolbox (Delorme and Makeig, 2004), was used for EEG data processing. The data were downsampled to $250 \mathrm{~Hz}$ for processing purposes and band-pass filtered between 0.5 and $100 \mathrm{~Hz}$. Three separate datasets were created for the auditory control task, the practise session and the main experiment. The data of the practise session were not used for the subsequent analyses. Ground and reference electrodes were removed from the datasets and the datasets were re-referenced to an average reference. All data were epoched from - 2000 to $4000 \mathrm{~ms}$ relative to auditory stimulus onset, including a $2000 \mathrm{~ms}$ baseline, the auditory stimulus presentation and, during the main experiment, the mental imagery part of the task (excluding target picture and response). Channels with a high noise level were removed (five channels on average). Eye movement artefacts were removed using an amplitude cut-off of $90 \mu \mathrm{V}$. Trials with residual eye movements and muscular artefacts were manually removed. In participants with a high number of eye movements artefact rejection was accomplished by performing an additional independent component analysis (ICA) and removing the eye movement related components (Jung et al., 2000).

After removal of artefacts either by manual trial rejection or ICA, the pre-processed epochs of all participants were subjected to a (second) ICA analysis (extended infomax, Makeig et al., 2004). An approximately equal number of components (depending on the final number of accepted channels) were extracted for each participant,

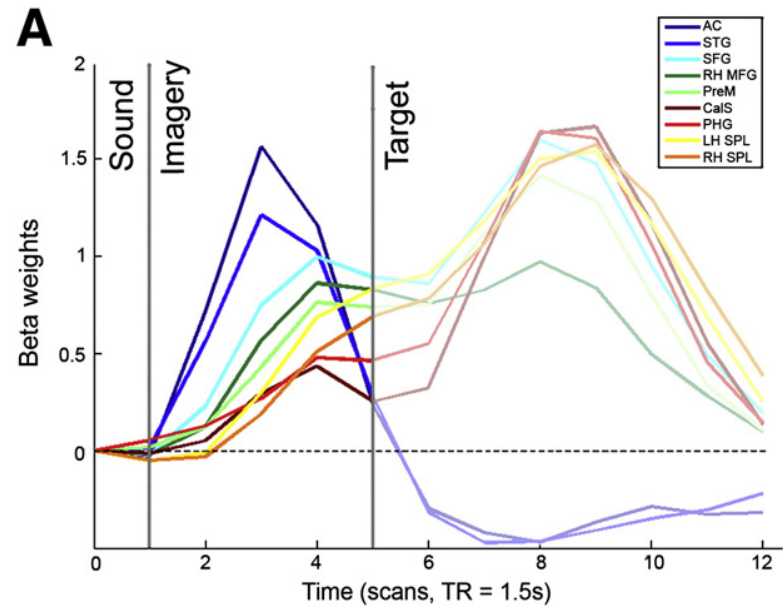

B

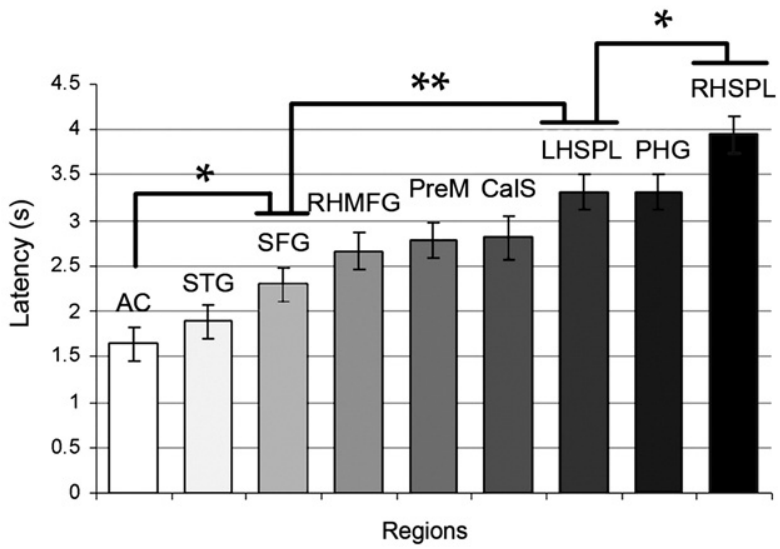

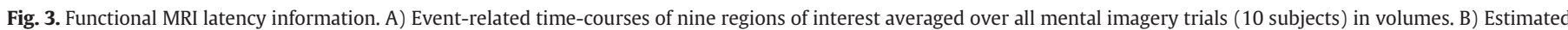
latency in seconds of nine regions of interest. * indicates significant difference with $\mathrm{p}<0.05$, ${ }^{* *}$ indicates significant difference with $\mathrm{p}<0.01$. Abbreviations as in Fig. 1. 
on average 58 for the auditory control task and 57 for the main experiment. The activity time courses of these components were further processed using time-frequency decompositions.

\section{Electroencephalography time-frequency analyses}

Time-frequency decompositions were performed on the trials of the selected components. Event related spectral perturbation (ERSP) and inter-trial coherence (ITC) plots were calculated for the components of each condition and participant separately. ERSP plots represent the changes in spectral power over a time window, compared to a baseline time window, averaged over trials. Here, $-2000 \mathrm{~ms}$ till $0 \mathrm{~ms}$ before auditory cue onset were used as baseline and the first $4000 \mathrm{~ms}$ of the imagery period were targeted for analyses (0-4000 ms after cue onset). Morlet wavelets (window of 209 samples $(836 \mathrm{~ms})$ per time bin) were used to extract spectral power changes in the frequency range $[1-40 \mathrm{~Hz}]$. A total of 4000 points (40 frequency bins and 100 temporal bins) were estimated in the selected time-frequency window. Five relevant ICs were selected based on across-subject consistency of topographic maps, spectral power plots, inter-trial coherence and time-frequency content (frequency bands and synchronisation/de-synchronisation patterns). In six out of seven subjects all ICs were present, while in one subject three ICs were present. Based on their topography, these components were labelled: "Central", "Left Posterior", "Right Posterior", "Right Anterior", and "Central Anterior" (see Fig. 4). Averaged event related spectral power for each subject and component (linear scale, baseline normalised) within three time-frequency bands (frequencies: theta [4-7 Hz], alpha [8-12 Hz], beta [12-30 Hz], 100 temporal bins) was used to perform statistical analysis between the auditory control task and the imagery task (paired $t$-test, $\mathrm{N}=7$ ).

\section{Reaction time based electroencephalography time-frequency analyses}

For each participant, reaction times (onset time button-press minus onset time target) of the correct trials were calculated. Trials were ordered and a median split was applied, resulting in a group of "fast" and "slow" trials per participant. EEG trials were labelled based on these two categories and corresponding epochs were selected and grouped. Averaged event related spectral power for each subject and component (linear scale, baseline normalised) within three time-frequency bands (frequencies: theta [4-7 Hz], alpha [8-12 Hz] and beta [12-30 Hz], 100 temporal bins) was used to perform statistical analysis between the imagery epochs that were either followed by fast or slow reaction times (paired $t$-test, $\mathrm{N}=7$ ).

\section{Source analyses of anterior components}

Source analysis of the anterior EEG components was performed using a four-shell spherical head model in the DIPFIT toolbox (Kavanagh et al., 1978), a dipole fitting procedure implemented in EEGlab. In each subject dipoles are fitted for the individual right anterior and central anterior components. After an automatic fitting procedure the resulting Talairach coordinates corresponding to the dipoles and the explained variance of the fitting were averaged across subjects $(\mathrm{N}=7)$.

\section{Results}

\section{Behavioural results}

The participants in the fMRI study $(\mathrm{N}=10)$ responded correctly on $92 \%(\mathrm{SD}=10.2)$ of the non-mirrored trials and $88 \%(\mathrm{SD}=11.3)$ of the mirrored trials with an average reaction time of $1823 \mathrm{~ms}$ $(\mathrm{SD}=642.3)$ for non-mirrored and $2008 \mathrm{~ms}(\mathrm{SD}=808.6)$ for mirrored trials. A paired sampled $t$-test showed that responses were significantly faster $(\mathrm{t}(9)=-2.32, \mathrm{p}<0.046)$ and more accurate $(\mathrm{t}(9)=$ $2.34, \mathrm{p}<0.044$ ) during the non-mirrored trials. During the EEG study participants $(\mathrm{N}=7)$ responded correctly on $91.1 \%(\mathrm{SD}=4.65)$ of the non-mirrored trials and 90.6\% $(\mathrm{SD}=4.06)$ of the mirrored trials with an average reaction time of $1366 \mathrm{~ms}(\mathrm{SD}=588.2)$ for nonmirrored and $1483 \mathrm{~ms}(\mathrm{SD}=512.9)$ for mirrored trials. A paired sampled $t$-test showed that responses were significantly faster $(\mathrm{t}(6)=$ $-3.349, \mathrm{p}<0.015$ ) during the non-mirrored trials.

\section{Spatio-temporal pattern of the imagery network}

Latency mapping of fMRI data (Figs. 2 and 3B) was performed during the imagery of scenes (excluding target picture) to reveal the imagery network nodes and their relative onset latency. The results showed that auditory cortex (AC) and superior temporal gyrus (STG) were activated earliest at the onset of the trial, together with parts of sub-cortical structures - thalamus (Th) and putamen $(\mathrm{Pu})$ and frontal regions - mesial superior frontal gyrus (SFG) (extending from the supplementary motor area to the anterior cingulate cortex) and pre-motor (PreM) cortex (indicated in dark green). Then, more extensive clusters in the mesial SFG, pre-motor cortex, thalamus and putamen became active as well as the right middle frontal gyrus (MFG), insula (INS), the calcarine sulcus (CalS) and several parietal regions, including the (left) superior parietal lobe (SPL), precuneus, intraparietal sulcus and parieto-occipital sulcus (light green to yellow). Subsequently, large parts of the (right) SPL, precuneus, medial and inferior occipital cortex and the parahippocampal gyrus (PHG) became active (orange). Last, parts of the right SPL, including intraparietal sulcus, and part of the right PHG were activated (dark orange to red). For an overview of all significantly activated regions see Table 1.

Further latency information on the fMRI data was gathered by event-related averages and a non-linear analytical procedure to estimate BOLD onsets of the activated regions. The ROI time-courses (Fig. 3A) visualise the different shapes and onsets of the hemodynamic responses in the active regions. The BOLD signal from the AC showed a steep increase with the onset of the auditory cue at the first TR. After an early peak around the third TR it showed a sharp decrease. The BOLD signal of the STG followed quickly after the auditory cortex response, displaying a similar shape. After the auditory stimulus (at the onset of the mental imagery), various regions showed an increase in BOLD signal around the second TR. The mesial SFG and the right MFG showed the steepest increase, closely followed by the PreM. Last, the PHG, the CalS and the left and right SPL showed an increase in BOLD signal. Due to similar BOLD shape, a distinguishable latency difference between left and right SPL could be observed.

The onset estimates provided by the additional BOLD Latency Mapping (BLM) analysis of the BOLD responses confirmed the described latency pattern of activation (Fig. 3B). Onset latency differences were compared between the earliest auditory and earliest frontal region ( $A C$ and $\mathrm{mSFG})(\mathrm{t}(8)=-3.806, \mathrm{p}<0.015)$, between the earliest frontal region and the earliest parietal region (mSFG and LHSPL) $(\mathrm{t}(8)=-6.656, \mathrm{p}<0.001)$ and between parietal cortices (LHSPL and RHSPL) $(\mathrm{t}(8)=-3.819, \mathrm{p}<0.021)$.

The EEG results during scene imagery were compared to an auditory control condition. Both datasets (imagery and control) were subjected to an ICA. Time-frequency content was derived to reveal functional relevance from the involved frequency bands and extract timing information. Fig. 4 shows the average ERSP plots of the five corresponding Independent Components (ICs) in the control and imagery condition at the following locations: central, central anterior, right anterior, left posterior, right posterior. The results from the paired $t$-tests revealed no significant difference at any time-point within the $[1-15 \mathrm{~Hz}]$ frequency range for the central IC $(t(6) \leq 2.2921, p>0.05)$. This component most likely reflects auditory processing of the cue (see average, top right Fig. 4), which is identical for the control and mental imagery task. The anterior and posterior ICs all showed an extensive change in spectral power during the imagery condition compared to the control condition. The right anterior 
Components

Control Condition

Imagery Condition

Box Average
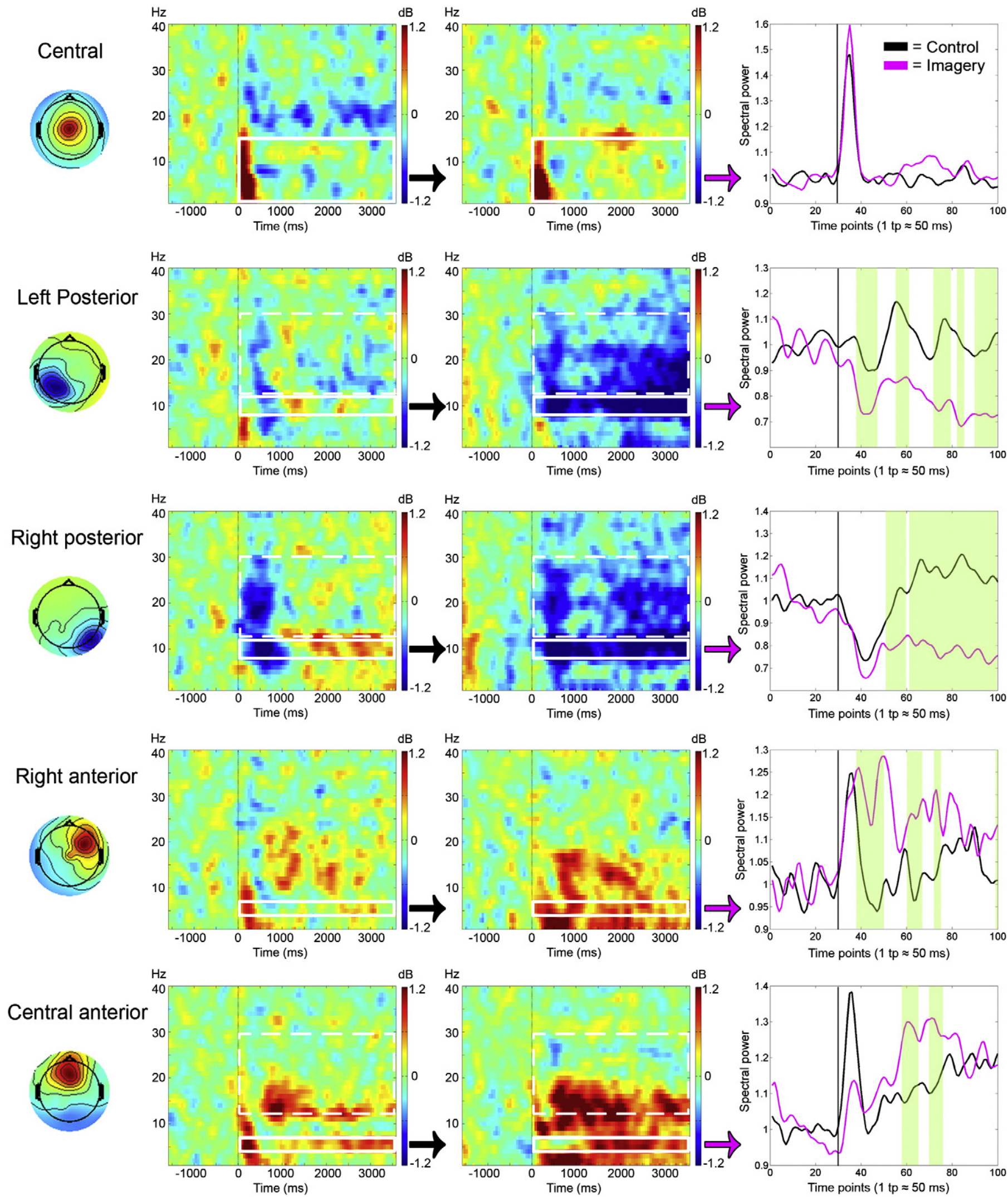

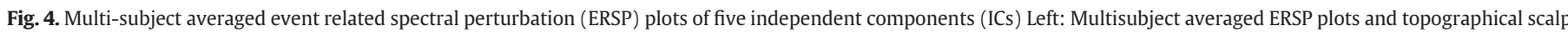

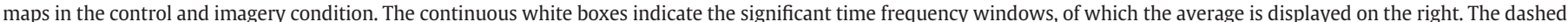

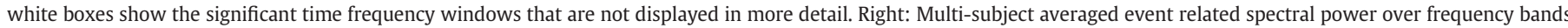

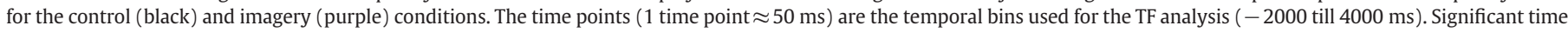
points $(p<0.05)$ are indicated by green lines. 
Table 1

Significantly activated regions during scene imagery. $\mathrm{L} / \mathrm{R} / \mathrm{m}$ indicates whether the region was in the left or right hemisphere or located medially.

\begin{tabular}{|c|c|c|c|c|c|}
\hline \multirow[t]{2}{*}{ Region } & \multirow{2}{*}{$\begin{array}{l}\mathrm{L} / \\
\mathrm{R} / \mathrm{m}\end{array}$} & \multirow{2}{*}{$\begin{array}{l}\text { Nr. } \\
\text { voxels }\end{array}$} & \multicolumn{3}{|c|}{ Talairach coordinates } \\
\hline & & & $\mathrm{x}$ & $\mathrm{y}$ & $\mathrm{z}$ \\
\hline \multicolumn{6}{|l|}{ Frontal } \\
\hline Middle frontal gyrus & $\mathrm{L}$ & 141 & -34 & 46 & 26 \\
\hline Middle frontal gyrus & $\mathrm{L}$ & 212 & -42 & 24 & 30 \\
\hline Middle frontal gyrus & $\mathrm{R}$ & 1011 & 32 & 39 & 30 \\
\hline Frontal eye fields & $\mathrm{L}$ & 577 & -41 & -2 & 32 \\
\hline Frontal eye fields & $\mathrm{R}$ & 2744 & 44 & 1 & 34 \\
\hline Premotor cortex & $\mathrm{L}$ & 4294 & -32 & -14 & 52 \\
\hline Premotor cortex & $\mathrm{R}$ & 3076 & 32 & -9 & 51 \\
\hline Superior frontal gyrus & $\mathrm{m}$ & 10,020 & 1 & 4 & 46 \\
\hline Insula & $\mathrm{L}$ & 1588 & -31 & 16 & 9 \\
\hline Insula & $\mathrm{R}$ & 2523 & 34 & 18 & 8 \\
\hline \multicolumn{6}{|l|}{ Subcortical } \\
\hline Thalamus & $\mathrm{L}$ & 1338 & -10 & -17 & 8 \\
\hline Thalamus & $\mathrm{R}$ & 1306 & 9 & -14 & 9 \\
\hline Putamen & $\mathrm{L}$ & 592 & -16 & 10 & 3 \\
\hline Putamen & $\mathrm{R}$ & 1252 & 16 & 9 & 6 \\
\hline Red nucleus & $\mathrm{L}$ & 222 & -5 & -23 & -3 \\
\hline Red nucleus & $\mathrm{R}$ & 369 & 6 & -22 & -2 \\
\hline Pulvinar & $\mathrm{L}$ & 274 & -19 & -25 & 1 \\
\hline Pulvinar & $\mathrm{R}$ & 639 & 18 & -25 & 1 \\
\hline \multicolumn{6}{|l|}{ Temporal } \\
\hline Superior temporal gyrus & $\mathrm{L}$ & 13,773 & -52 & -21 & 7 \\
\hline Superior temporal gyrus & $\mathrm{R}$ & 11,863 & 54 & -19 & 3 \\
\hline Parahippocampal gyrus & $\mathrm{L}$ & 1937 & -28 & -35 & -14 \\
\hline Parahippocampal gyrus & $\mathrm{R}$ & 659 & 27 & -31 & -13 \\
\hline Inferior temporal gyrus & $\mathrm{L}$ & 553 & -46 & -52 & -11 \\
\hline \multicolumn{6}{|l|}{ Parietal } \\
\hline Superior parietal lobe & $\mathrm{L}$ & 11,037 & -18 & -70 & 39 \\
\hline Superior parietal lobe & $\mathrm{R}$ & 9708 & 18 & -67 & 40 \\
\hline Intraparietal sulcus & $\mathrm{L}$ & 5237 & -35 & -47 & 38 \\
\hline Intraparietal sulcus & $\mathrm{R}$ & 9708 & 18 & -67 & 40 \\
\hline Precuneus & $\mathrm{L}$ & 1507 & -4 & -76 & 34 \\
\hline Precuneus & $\mathrm{R}$ & 1523 & 4 & -75 & 37 \\
\hline Parieto-occipital sulcus & $\mathrm{L}$ & 2017 & -17 & -65 & 17 \\
\hline Parieto-occipital sulcus & $\mathrm{R}$ & 3918 & 16 & -63 & 19 \\
\hline \multicolumn{6}{|l|}{ Occipital } \\
\hline Cuneus & $\mathrm{L}$ & 5557 & -6 & -77 & 8 \\
\hline Cuneus & $\mathrm{R}$ & 3283 & 4 & -78 & 13 \\
\hline Lingual gyrus & $\mathrm{L}$ & 8678 & -9 & -77 & -11 \\
\hline Lingual gyrus & $\mathrm{R}$ & 8435 & 10 & -78 & -9 \\
\hline Inferior occipital gyrus & $\mathrm{L}$ & 1356 & -24 & -85 & -2 \\
\hline Middle occipital gyrus & $\mathrm{L}$ & 3821 & -29 & -78 & 15 \\
\hline Calcarine sulcus & $\mathrm{m}$ & 14,980 & 0 & -74 & 3 \\
\hline
\end{tabular}

IC and the central anterior IC showed extensive spectral power increases (synchronisation) in the theta, alpha and beta bands during imagery. The right anterior IC showed significant differences $(\mathrm{t}(5) \leq-2.5750, \mathrm{p}<0.05)$ between conditions in the theta $[4-7 \mathrm{~Hz}]$ frequency band at several time-points (see Fig. 4, Box Average, green lines). The central anterior IC showed significant differences between conditions in the theta $[4-7 \mathrm{~Hz}](\mathrm{t}(6) \leq-2.7099, \mathrm{p}<0.05$; displayed) and beta [12-30 Hz] $(\mathrm{t}(6) \leq-2.5483, \mathrm{p}<0.05$; not displayed as average) frequency bands at several time-points (see Fig. 4, Box Average, green lines). Left and right posterior ICs showed a larger decrease in spectral power (de-synchronisation) in the alpha and beta band during the imagery condition. There were significant differences between conditions in the alpha [8-12 Hz] (Left: $\mathrm{t}(6) \geq 2.4671, \mathrm{p}<0.05$; Right: $\mathrm{t}(5) \geq 2.6295, \mathrm{p}<0.05$ ) (displayed) and beta $[12-30 \mathrm{~Hz}$ ] (Left: $\mathrm{t}(6) \geq 2.4549, \mathrm{p}<0.05$; Right: $\mathrm{t}(5) \geq 2.7391$, $\mathrm{p}<0.05$, not displayed as average) frequency bands in large time windows for both ICs (see Fig. 4, Box Average, green lines). Similar to the fMRI results, the spectral power during mental imagery showed an earlier significant divergence from the control condition in the left posterior IC compared to the right posterior IC.

\section{Calcarine sulcus involvement}

In 8 out of 10 subjects activity along the calcarine sulcus was observed during the mental imagery of scenes. In Fig. 5 the calcarine sulcus activity of a single participant is presented. The brain activity during imagery (target-related activity is excluded) is overlaid in purple on a retinotopic map of the participant (acquired in an earlier session), showing V1 involvement. Time courses corresponding to patches in left and right V1 are shown on the left and right side of Fig. 5, reflecting the BOLD signal change during imagery and after the visual target (target onset indicated by red line). The time courses show a clear increase in BOLD signal during the imagery period, with a small decrease at the end of the period, followed by a strong increase with the onset of the target. The lower maps in Fig. 5 show an extensive imagery-related activation of V1 and higher visual areas. During EEG measurements no consistent EEG component related to visual processing could be established.

\section{Predicting performance from frontal activation during imagery}

In order to determine which of the regions activated during mental imagery predict later performance on the scene imagery task, both fMRI and EEG trials were split according to reaction times. The fMRI data median split in fast versus slow reaction time trials revealed a region in the mesial SFG that showed a significant difference (higher BOLD signal for slow reaction time trials) for the tested contrast (Fig. 6A, 341 voxels, q (FDR) <0.05).

The same procedure was performed on the EEG data. When splitting the trials according to behavioural performance, only one of five components, the central anterior IC, showed a difference between the "fast" and the "slow" condition (Fig. 6B). Paired t-tests revealed significant differences $(p<0.05)$ in the theta $[4-7 \mathrm{~Hz}]$, alpha [8-12 Hz] and beta [12-30 Hz] bands at time-points indicated in green, showing that higher spectral power during mental imagery is linked to faster response times on the subsequent behavioural task with target pictures. The other four components showed no significant difference between "fast" or "slow" reaction time trials.

\section{Source analysis anterior components}

The frontal ICs with right anterior and central anterior distribution were subjected to an automated dipole fitting procedure. The source of the right anterior component was localised to the right middle frontal gyrus with average Talairach coordinates $(27 \pm 5.38,25 \pm$ $18.65,25 \pm 12.13)$ explaining on average $89 \%(S E=5.19)$ of the variance. Fig. 7 shows the right anterior source to overlap with the right frontal fMRI cluster. The central anterior source was localised to the mesial superior frontal gyrus with average Talairach coordinates $(2 \pm 7.28,22 \pm 11.67,23 \pm 15.54)$, explaining on average $95 \%$ $(\mathrm{SE}=7.20)$ of variance, slightly anterior to the mesial superior frontal fMRI cluster (see Fig. 7). These results confirm the initial observation based on IC topographies, suggesting a link between mesial superior frontal gyrus and the central anterior component and right middle frontal gyrus and the right anterior component.

\section{Discussion}

In this study we investigated the spatio-temporal pattern of activation within the distributed scene imagery brain network. Our results showed an early activation of mesial SFG, right MFG and premotor cortex in both fMRI and EEG data. The activation of frontal regions could be linked to increased synchronisation in theta and beta bands. Especially the activation of mesial SFG during imagery 


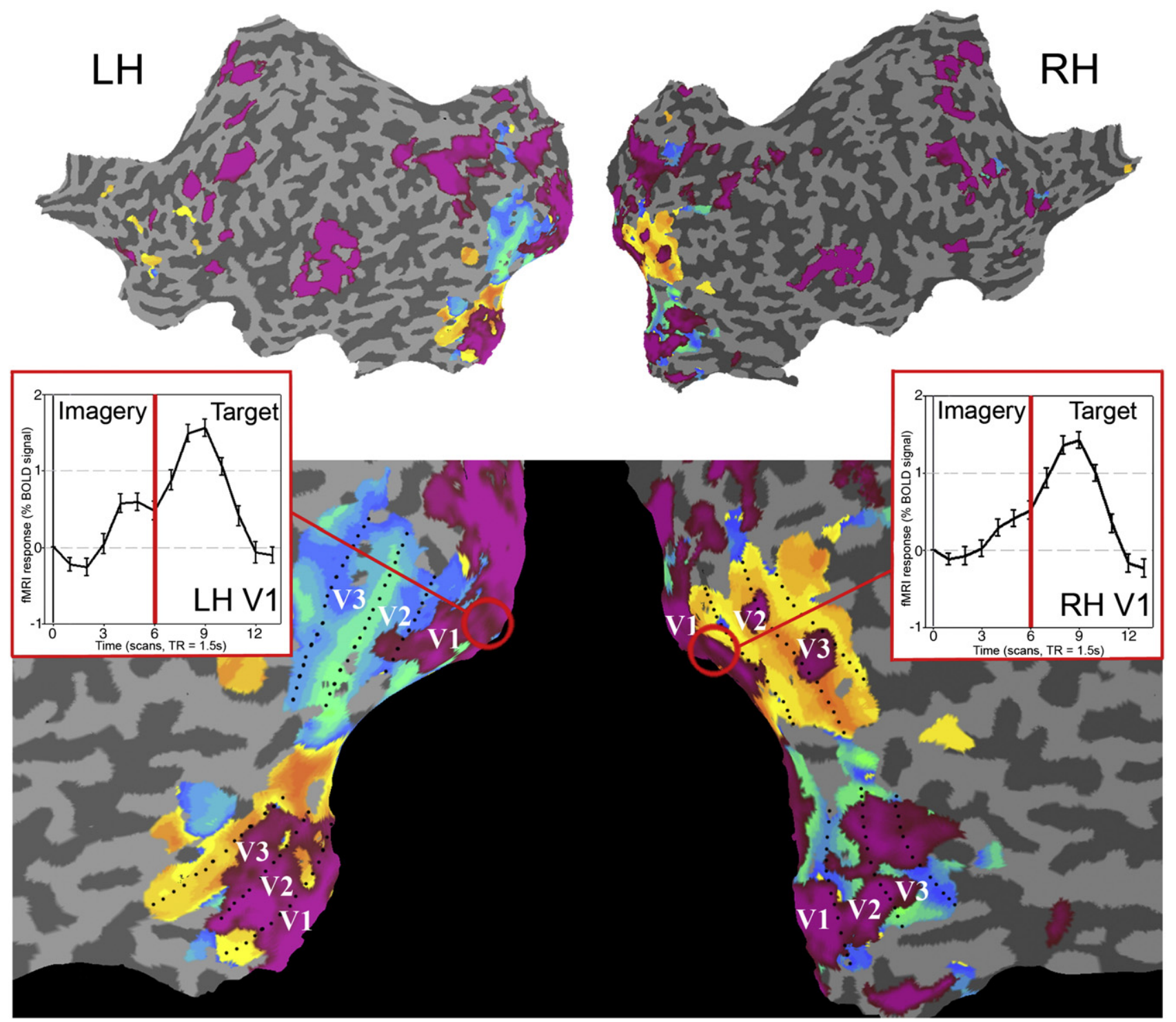

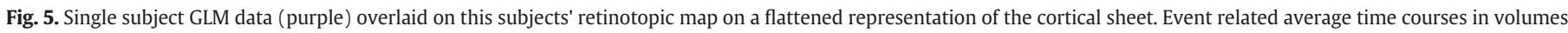
of two regions of interest in primary visual cortex are presented on the left and right side of the figure.

seemed to be of crucial importance in subsequent task performance. Later on during imagery, remote regions in visual cortex, ventrotemporal cortex and parietal cortex were activated, of which the latter were linked to de-synchronisation in alpha and beta bands. We summarise these results in a neuro-anatomical model of scene imagery (Fig. 8), and discuss the details below.

\section{The frontal relay station}

During the fMRI session, several frontal regions were found to be active: mesial SFG, right MFG and premotor cortex. The mesial SFG seemed to be most crucial during our mental imagery task, as it was activated earliest and predicted later task performance. The EEG data revealed a component with remarkable correspondence in location and behavioural relevance; the central anterior component. In fact, in agreement with our source analysis results, several studies support the localization of the midline frontal theta rhythm to anterior cingulate and medial prefrontal cortex (Asada et al., 1999; Gevins et al., 1997; Jensen and Tesche, 2002). We propose that beta synchronisation in mesial SFG reflects integration of information into a rehearsal set as was shown by Onton et al. (2005). Moreover, theta synchronisation in mesial SFG is related to mental effort, attention and working memory maintenance and recall (Gevins et al., 1997; Jensen and Tesche, 2002; Rugg and Venables, 1980). This is plausible in the context of working memory studies that suggested the mesial SFG to perform integration of visual and spatial features (Mitchell et al., 2000; Munk et al., 2002; Prabhakaran et al., 2000) and executive function (D'Esposito et al., 1995; Talati and Hirsch, 2005). This integrative and essential role of the mesial SFG is further supported by the results of the prediction of reaction times in both the fMRI and EEG data. Both datasets revealed the activity in this central anterior region to be predictive of imagery performance (see Fig. 6), while other regions were not. Interestingly, mesial SFG in the fMRI data and the midline anterior IC in the EEG data showed opposite patterns in relation to task performance (see Fig. 6). A higher BOLD signal during mental imagery predicted slower reaction times, while stronger synchronisation in the theta, alpha and beta bands during mental imagery predicted faster reaction times. One could theorise that during trials in which the participant found it difficult to imagine the scene, more interneurons were addressed to inhibit irrelevant input (Swadlow, 2003), leading to more oxygen consumption and higher BOLD signal, but less neuronal activity as measured by EEG (Buzsaki et al., 2007; Ekstrom, 2010). Alternatively, SFG activity could be related to response preparation. However, such an explanation is highly 


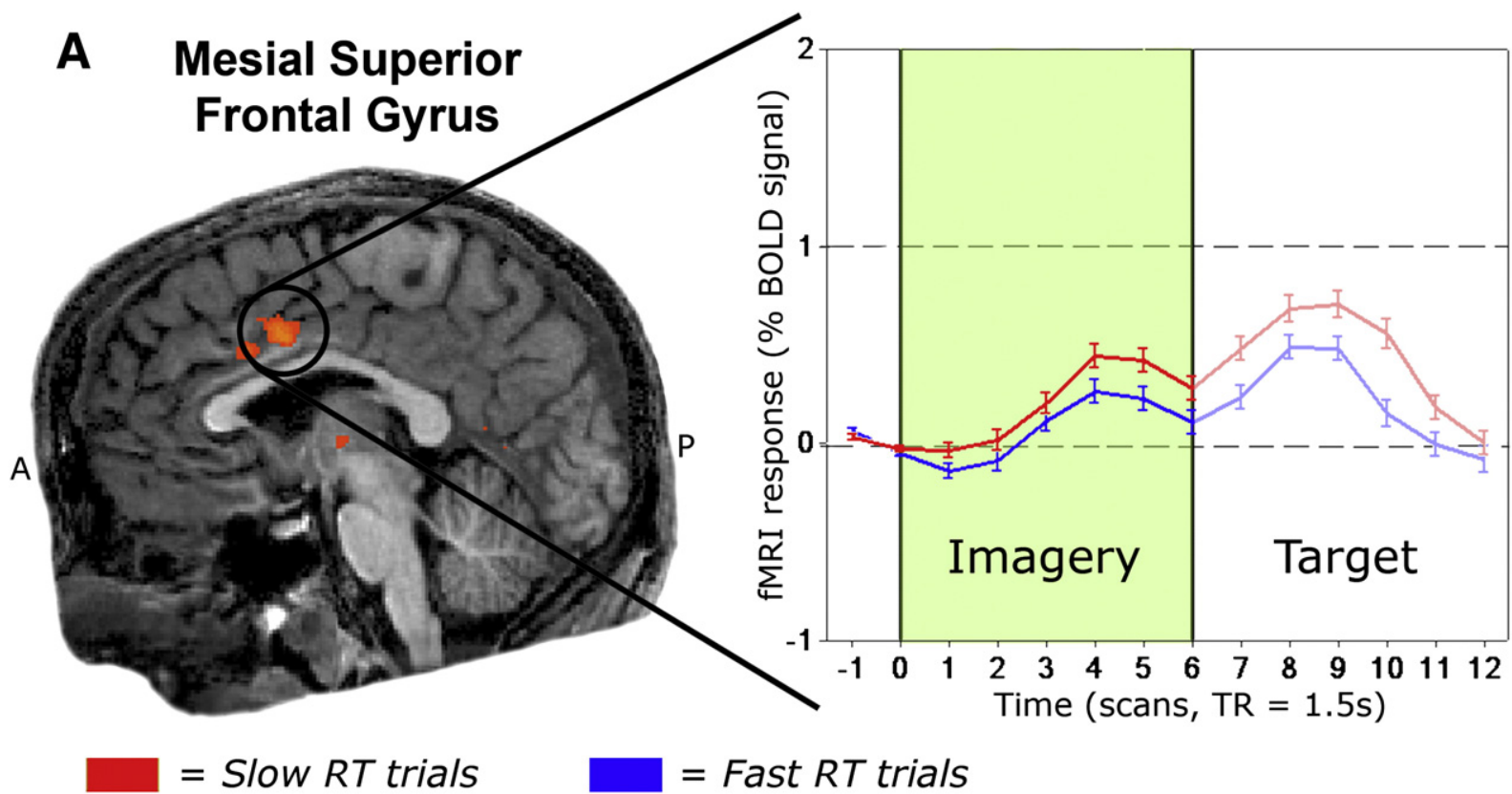

B Central Anterior IC
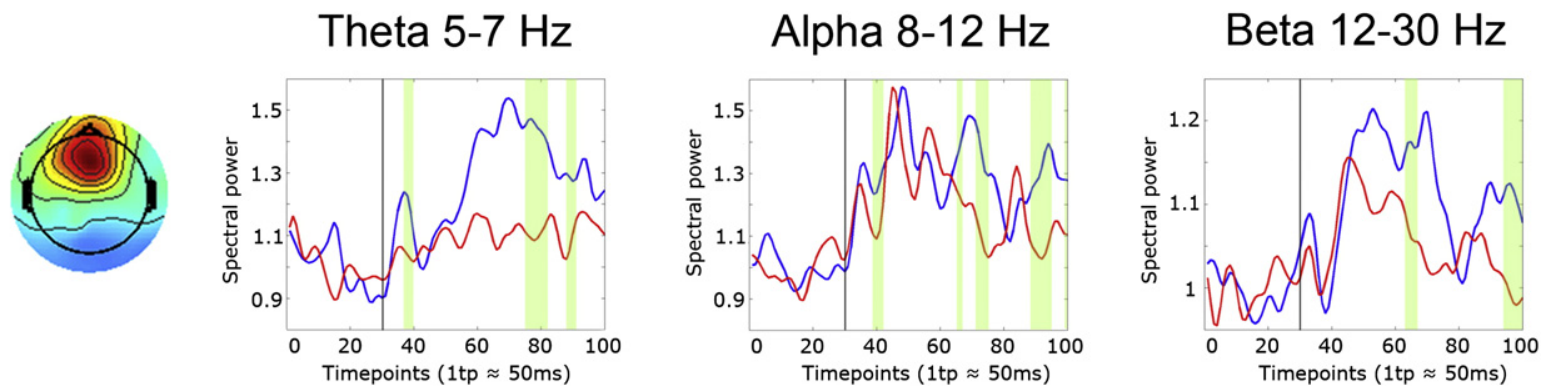

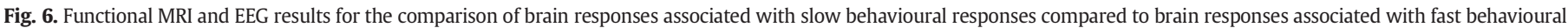

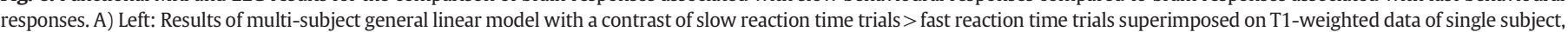

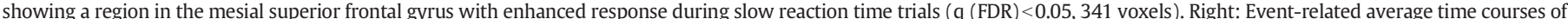

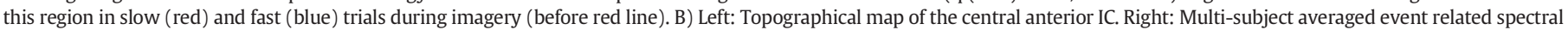
power plots of the central anterior IC ( 1 time point $\approx 50 \mathrm{~ms}$ ) with significant differences (green) in the theta (4-7 Hz), alpha (8-12 Hz) and beta range ( $12-30 \mathrm{~Hz}$ ).

\section{Dipole source modelling}

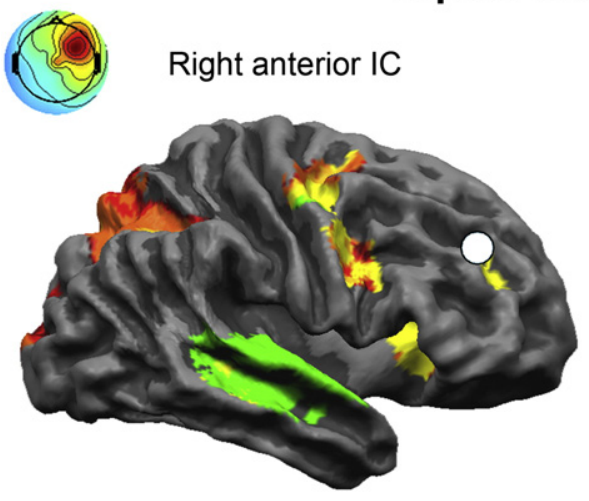

$\operatorname{TAL}(27,25,25)$

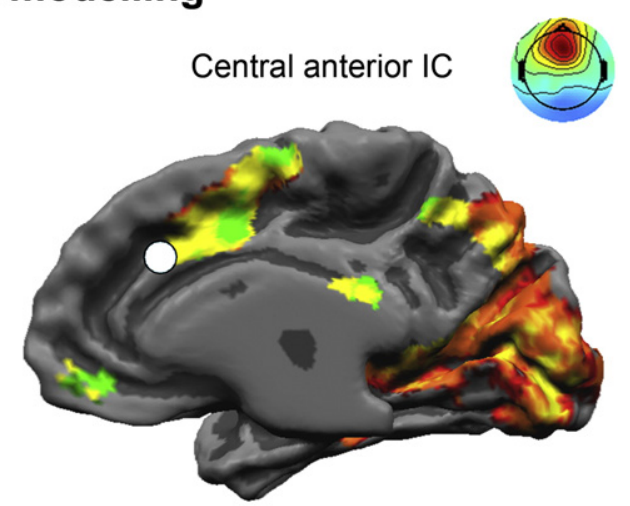

$\operatorname{TAL}(2,22,23)$

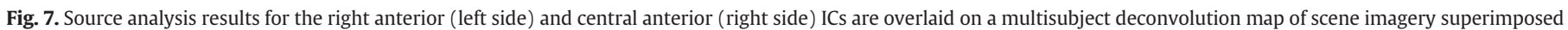
on a cortex-based aligned (10 subjects) representation of the right hemisphere. Average Talairach coordinates of dipole locations are displayed. 


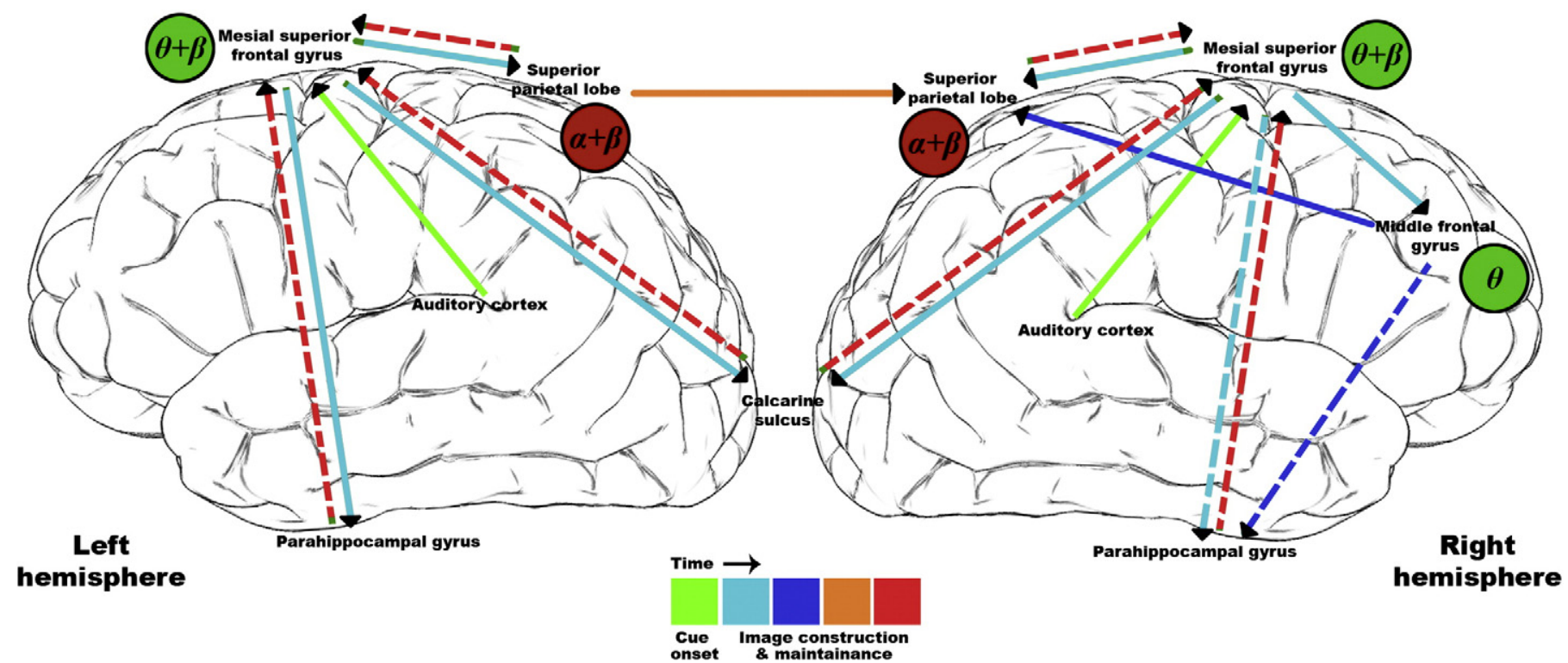

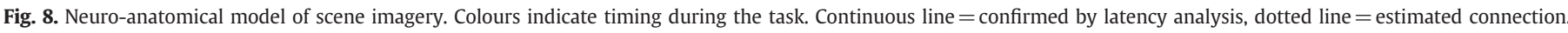

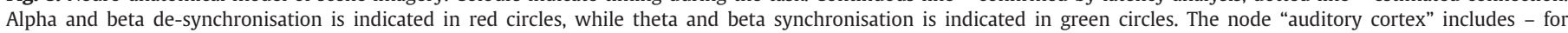

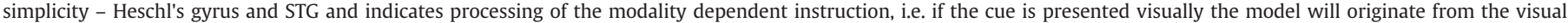
cortex. While feedback connections are indicated in red (last) it is assumed that feedback takes place continuously.

unlikely as the "imagery" period was extensive and the visual targets had a variable onset. The role of general mental effort in mesial SFG activation is harder to disentangle, but - if present - is more likely to modulate the functional role of the region (i.e. more effort into the integration of information), rather than reflect its functionality. Similarly, we cannot exclude the possibility that the differences between slow and fast reaction times (and related fMRI/EEG effects) may partly originate from an overall improvement of subjects' performance (learning effect). However, we did not observe systematic learning during the measurement sessions and thus the contribution of such a component seems rather limited.

Another correspondence in the fMRI and EEG results (confirmed by the dipole fitting results) is the right lateralization of a frontal region, the right MFG. Again, the theta synchronisation in the right anterior component that is suggested to reflect memory retrieval and attention (dark blue arrows Fig. 8) (Bastiaansen et al., 2005; Deiber et al., 2007; Petsche et al., 1992), seems to match the function attributed by neuroimaging studies of working memory (Buckner et al., 1996; Tulving et al., 1996).

We thus propose that right and midline frontal theta and beta oscillations contribute to the retrieval and integration of visuo-spatial information, possibly by streamlining neuronal activity with help of interneurons, as reflected in right MFG and mesial SFG BOLD activity. Whereas in mental imagery research so far the focus laid on activity in ventral and dorsal stream regions, the mesial SFG in fact seems to be the conductor within this orchestra of brain regions (see light blue and red arrows in Fig. 8). It may establish an integrated scene representation by working closely together with remote parietal regions to encode the spatial sketch of the scene and with occipitaltemporal regions to encode the detailed visual representations of the objects. Further investigations that combine fMRI and EEG/MEG with effective connectivity methods (e.g. Friston et al., 2003; Roebroeck et al., 2005; Valdes-Sosa et al., 2011) are needed to test this hypothesis. However, methodological advances in effective connectivity need to be made in order to deal satisfactorily with the complexity that a data set such as the one presented here poses to this type of modelling (e.g. high number of nodes, interdependency of frequency bands).

\section{Remote regions: parietal activity}

While the parietal regions are often regarded as a starting point for (spatial) mental imagery processing, our studies showed a late involvement of bilateral SPL, precuneus and intraparietal sulcus (IPS). They seem to be drawn on by the frontal regions during the later stages of image construction. Likewise, ICA during EEG measurements revealed two components (bilateral) at parietal electrode sites, which showed a later extensive de-synchronisation in the alpha and beta band. Consistently with previous studies, the parietal cortex also during our task is likely to be involved in the retrieval and construction of spatial representations. While in fMRI the extensive parietal cluster could be subdivided based on anatomical landmarks, the EEG components could not be separated into different clusters. However, the EEG data did also show a latency difference (Fig. 4) between left and right parietal clusters, confirming the fMRI results (Spatio-temporal pattern of the imagery network section). Previous studies suggested that this latency difference indicated a functional segregation within a spatial imagery context, where the left parietal cortex is involved in the generation of spatial representations and the right parietal cortex in spatial comparison (Formisano et al., 2002; Sack et al., 2005; Sack et al., 2002). Since no spatial comparison is made during the imagery period in our study, we propose to extent this view to a more general hemispheric specialisation where the left SPL could be more involved in early image construction and right SPL in later image integration (and subsequent inspection) (orange arrow Fig. 8).

When looking into more spatial detail, the separate parietal regions seem to have their own specific functions. While the precuneus, which is highly connected with the mesial SFG, thalamus and other parietal regions (Cavanna and Trimble, 2006), might be involved in retrieval of spatial memory content (Daselaar et al., 2009), the SPL and IPS have been shown to reflect processing of these spatial properties by constructing and integrating the mental image (Alivisatos and Petrides, 1997; Formisano et al., 2002; Goebel et al., 1998; Mellet et al., 2000; Podzebenko et al., 2002; Trojano et al., 2000). The precuneus may then facilitate information exchange for integration of spatial features of the scene to mesial SFG. The functions of memory retrieval and maintenance are further supported by the presence of 
alpha and beta synchronisation in parietal cortex, which are respectively suggested to reflect memory retrieval and task complexity (Klimesch, 1997; Klimesch et al., 2000; Neuper and Pfurtscheller, 2001) and working memory retrieval and maintenance (Babiloni et al., 2004; Deiber et al., 2007; Onton et al., 2005; Tallon-Baudry et al., 2001; Tallon-Baudry et al., 1998).

Overall our results in parietal cortex suggest that these regional fMRI activations are linked to the induced alpha and beta desynchronisation with posterior topography observed during EEG, retrieving and processing the spatial properties of the mental image. This observation is consistent with recent studies employing simultaneous EEG-fMRI measurements during resting state, in which a negative correlation is reported between power of neuronal oscillations in the alpha and beta frequency range and BOLD activation in the dorsal attentional network (Mantini et al., 2007).

\section{Remote regions: occipital-temporal activity}

While the parietal regions seem to contribute to the construction of spatial relations, two other sets of remote regions are drawn on by frontal regions during scene imagery: the (early) visual cortex and the parahippocampal cortex (PHG). Although we found no corresponding components in the EEG experiment, these activation sites nevertheless seem to be relevant for scene imagery, as suggested by previous research. The PHG is here most likely involved in memory retrieval of objects (Hayes et al., 2007; Prince et al., 2009). Like the SPL and precuneus, the PHG conveys information to the frontal cortex, where information is integrated. This idea is supported by the finding of projections from the PHG to the medial prefrontal cortex in rhesus monkeys (Bachevalier et al., 1997).

We also clearly revealed an early activation of primary visual cortex during our scene imagery task. Although the involvement of primary visual cortex during mental imagery is still debated as some studies report activation (Klein et al., 2004; Kosslyn et al., 1999; Le Bihan et al., 1993), while others do not (D'Esposito et al., 1997; Knauff et al., 2000), our findings provide strong evidence for the involvement of primary visual cortex in visual imagery. This early visual cortex (EVC) activation as revealed with the current paradigm is in disagreement with our previous imagery studies where we could not find early visual cortex involvement during spatial imagery (Formisano et al., 2002; Trojano et al., 2002; Trojano et al., 2000). Unlike our previous studies, the current imagery paradigm required a detailed inspection of the realistic mental image, including objects, which apparently was decisive for the EVC activity reported here (Kosslyn and Thompson, 2003). Altogether, the occipital-temporal cortex encodes the visually detailed objects and may continuously convey this information (red arrow Fig. 8) to mesial SFG for integrating and maintaining a scene representation.

In EEG, we did not find an IC that could be associated with the involvement of the occipital-temporal visual regions during mental imagery. This discrepancy between EEG and fMRI findings may result from a lower sensitivity of EEG for these neuronal sources. This is further supported by the fact that ICs reflecting visual processing were found in the analysis of the EEG responses to the target presentation (data not shown), which evoked in fMRI - in the same visual regions - much larger BOLD responses than those observed during imagery (Fig. 3A). Finally, the medial-ventral position of the parahippocampal gyrus makes it highly difficult to measure electrical signals from this region.

\section{Conclusions}

The results of our study suggest that the frontal regions, especially the mesial SFG, are orchestrating the visual scene imagery network. By combining the spectro-temporal information from the EEG data with the spatio-temporal information from the fMRI we propose a neuro-anatomical model that links an early synchronisation in theta and beta oscillations with anterior distribution to the fMRI activation of right and central frontal regions, reflecting retrieval and integration of information. These frontal regions are suggested to drawn on remote parietal regions for retrieval and representation of the spatial content of the scene and occipital-temporal regions for detailed visual representation of the objects.

\section{Acknowledgments}

This work was supported by a cooperation Grant from the Deutsche Forschungsgemeinschaft (DFG) and the Netherlands Organization for Scientific Research (NWO) (DN 55-19). E.F. was supported by NWO MaGW-VIDI grant 452-04-330. A.T.S. was supported by NWO grant 452-06-003.

\section{References}

Alivisatos, B., Petrides, M., 1997. Functional activation of the human brain during mental rotation. Neuropsychologia 35, 111-118.

Asada, H., Fukuda, Y., Tsunoda, S., Yamaguchi, M., Tonoike, M., 1999. Frontal midline theta rhythms reflect alternative activation of prefrontal cortex and anterior cingulate cortex in humans. Neurosci. Lett. 274, 29-32.

Babiloni, C., Babiloni, F., Carducci, F., Cincotti, F., Vecchio, F., Cola, B., Rossi, S., Miniussi, C., Rossini, P.M., 2004. Functional frontoparietal connectivity during short-term memory as revealed by high-resolution EEG coherence analysis. Behav. Neurosci. 118, 687-697.

Bachevalier, J., Meunier, M., Lu, M.X., Ungerleider, L.G., 1997. Thalamic and temporal cortex input to medial prefrontal cortex in rhesus monkeys. Exp. Brain Res. 115, 430-444

Barrett, J., Ehrlichman, H., 1982. Bilateral hemispheric alpha activity during visual imagery. Neuropsychologia 20, 703-708.

Bastiaansen, M.C., van der Linden, M., Ter Keurs, M., Dijkstra, T., Hagoort, P., 2005. Theta responses are involved in lexical-semantic retrieval during language processing. J. Cogn. Neurosci. 17, 530-541.

Bhattacharya, J., Petsche, H., 2005. Drawing on mind's canvas: differences in cortical integration patterns between artists and non-artists. Hum. Brain Mapp. 26, 1-14.

Buckner, R.L., Raichle, M.E., Miezin, F.M., Petersen, S.E., 1996. Functional anatomic studies of memory retrieval for auditory words and visual pictures. J. Neurosci. 16, 6219-6235.

Buzsaki, G., Kaila, K., Raichle, M., 2007. Inhibition and brain work. Neuron 56, 771-783.

Cavanna, A.E., Trimble, M.R., 2006. The precuneus: a review of its functional anatomy and behavioural correlates. Brain 129, 564-583.

Cohen, M.S., Kosslyn, S.M., Breiter, H.C., DiGirolamo, G.J., Thompson, W.L., Anderson, A.K., Brookheimer, S.Y., Rosen, B.R., Belliveau, J.W., 1996. Changes in cortical activity during mental rotation. A mapping study using functional MRI. Brain 119 (Pt 1), 89-100.

Dale, A.M., Buckner, R.L., 1997. Selective averaging of rapidly presented individual trials using fMRI. Hum. Brain Mapp. 5, 329-340.

Daselaar, S.M., Prince, S.E., Dennis, N.A., Hayes, S.M., Kim, H., Cabeza, R., 2009. Posterior midline and ventral parietal activity is associated with retrieval success and encoding failure. Front. Hum. Neurosci. 3, 13.

Deiber, M.P., Missonnier, P., Bertrand, O., Gold, G., Fazio-Costa, L., Ibanez, V., Giannakopoulos, P., 2007. Distinction between perceptual and attentional processing in working memory tasks: a study of phase-locked and induced oscillatory brain dynamics. J. Cogn. Neurosci. $19,158-172$.

Delorme, A., Makeig, S., 2004. EEGLAB: an open source toolbox for analysis of single-trial EEG dynamics including independent component analysis. J. Neurosci. Methods $134,9-21$.

D'Esposito, M., Detre, J.A., Alsop, D.C., Shin, R.K., Atlas, S., Grossman, M., 1995. The neural basis of the central executive system of working memory. Nature 378, 279-281.

D'Esposito, M., Detre, J.A., Aguirre, G.K., Stallcup, M., Alsop, D.C., Tippet, L.J., Farah, M.J., 1997. A functional MRI study of mental image generation. Neuropsychologia 35, $725-730$

Ekstrom, A., 2010. How and when the fMRI BOLD signal relates to underlying neural activity: the danger in dissociation. Brain Res. Rev. 62, 233-244.

Farah, M.J., Hammond, K.M., Levine, D.N., Calvanio, R., 1988. Visual and spatial mental imagery: dissociable systems of representation. Cogn. Psychol. 20, 439-462.

Formisano, E., Goebel, R., 2003. Tracking cognitive processes with functional MRI mental chronometry. Curr. Opin. Neurobiol. 13, 174-181.

Formisano, E, Linden, D.E, Di Salle, F, Trojano, L, Esposito, F, Sack, A.T, Grossi, D. Zanella, F.E., Goebel, R., 2002. Tracking the mind's image in the brain I: timeresolved fMRI during visuospatial mental imagery. Neuron 35, 185-194.

Friston, K.J., Harrison, L., Penny, W., 2003. Dynamic causal modelling. Neurolmage 19, 1273-1302.

Genovese, C.R., Lazar, N.A., Nichols, T., 2002. Thresholding of statistical maps in functional neuroimaging using the false discovery rate. Neurolmage $15,870-878$.

Gevins, A., Smith, M.E., McEvoy, L., Yu, D., 1997. High-resolution EEG mapping of cortical activation related to working memory: effects of task difficulty, type of processing, and practice. Cereb. Cortex 7, 374-385.

Gill, H.S., O'Boyle, M.W., Hathaway, J., 1998. Cortical distribution of EEG activity for component processes during mental rotation. Cortex 34, 707-718. 
Goebel, R., Linden, D.E., Lanfermann, H., Zanella, F.E., Singer, W., 1998. Functional imaging of mirror and inverse reading reveals separate coactivated networks for oculomotion and spatial transformations. Neuroreport 9, 713-719.

Goebel, R., Esposito, F., Formisano, E., 2006. Analysis of functional image analysis contest (FIAC) data with brainvoyager QX: from single-subject to cortically aligned group general linear model analysis and self-organizing group independent component analysis. Hum. Brain Mapp. 27, 392-401.

Goldstein, E.B., 2002. Sensation and Perception, 5th edn. Wadsworth, Belmont, CA.

Hayes, S.M., Nadel, L., Ryan, L., 2007. The effect of scene context on episodic object recognition: parahippocampal cortex mediates memory encoding and retrieval success. Hippocampus 17, 873-889.

Ishai, A., Ungerleider, L.G., Haxby, J.V., 2000. Distributed neural systems for the generation of visual images. Neuron 28, 979-990.

Ishai, A., Haxby, J.V., Ungerleider, L.G., 2002. Visual imagery of famous faces: effects of memory and attention revealed by fMRI. NeuroImage 17, 1729-1741.

Jensen, O., Tesche, C.D., 2002. Frontal theta activity in humans increases with memory load in a working memory task. Eur. J. Neurosci. 15, 1395-1399.

Jung, T.P., Makeig, S., Humphries, C., Lee, T.W., McKeown, M.J., Iragui, V., Sejnowski, T.J., 2000. Removing electroencephalographic artifacts by blind source separation. Psychophysiology 37, 163-178.

Kavanagh, R.N., Darcey, T.M., Lehmann, D., Fender, D.H., 1978. Evaluation of methods for three-dimensional localization of electrical sources in the human brain. IEEE Trans. Biomed. Eng. 25, 421-429.

Klein, I., Dubois, J., Mangin, J.F., Kherif, F., Flandin, G., Poline, J.B., Denis, M., Kosslyn, S.M., Le Bihan, D., 2004. Retinotopic organization of visual mental images as revealed by functional magnetic resonance imaging. Brain Res. Cogn. Brain Res. 22, 26-31.

Klimesch, W., 1997. EEG-alpha rhythms and memory processes. Int. J. Psychophysiol. 26, 319-340.

Klimesch, W., Doppelmayr, M., Rohm, D., Pollhuber, D., Stadler, W., 2000. Simultaneous desynchronization and synchronization of different alpha responses in the human electroencephalograph: a neglected paradox? Neurosci. Lett. 284, 97-100.

Knauff, M., Kassubek, J., Mulack, T., Greenlee, M.W., 2000. Cortical activation evoked by visual mental imagery as measured by fMRI. Neuroreport 11, 3957-3962.

Kosslyn, S.M., Thompson, W.L., 2003. When is early visual cortex activated during visual mental imagery? Psychol. Bull. 129, 723-746.

Kosslyn, S.M., Behrmann, M., Jeannerod, M., 1995. The cognitive neuroscience of mental imagery. Neuropsychologia 33, 1335-1344.

Kosslyn, S.M., Pascual-Leone, A., Felician, O., Camposano, S., Keenan, J.P., Thompson, W.L., Ganis, G., Sukel, K.E., Alpert, N.M., 1999. The role of area 17 in visual imagery: convergent evidence from PET and rTMS. Science 284, 167-170.

Kosslyn, S.M., Ganis, G., Thompson, W.L., 2001. Neural foundations of imagery. Nat. Rev. Neurosci. 2, 635-642.

Lamm, C., Windischberger, C., Leodolter, U., Moser, E., Bauer, H., 2001. Evidence for premotor cortex activity during dynamic visuospatial imagery from single-trial functional magnetic resonance imaging and event-related slow cortical potentials. Neurolmage $14,268-283$.

Le Bihan, D., Turner, R., Zeffiro, T.A., Cuenod, C.A., Jezzard, P., Bonnerot, V., 1993. Activation of human primary visual cortex during visual recall: a magnetic resonance imaging study. Proc. Natl. Acad. Sci. U. S. A. 90, 11802-11805.

Levine, D.N., Warach, J., Farah, M., 1985. Two visual systems in mental imagery: dissociation of "what" and "where" in imagery disorders due to bilateral posterior cerebral lesions. Neurology 35, 1010-1018.

Linden, D.E., Thornton, K., Kuswanto, C.N., Johnston, S.J., van de Ven, V., Jackson, M.C., 2011. The brain's voices: comparing nonclinical auditory hallucinations and imagery. Cereb Cortex 21, 330-337.

Lu, Y., Bagshaw, A.P., Grova, C., Kobayashi, E., Dubeau, F., Gotman, J., 2006. Using voxel-specific hemodynamic response function in EEG-fMRI data analysis. NeuroImage 32, 238-247.

Lu, Y., Grova, C., Kobayashi, E., Dubeau, F., Gotman, J., 2007. Using voxel-specific hemodynamic response function in EEG-fMRI data analysis: an estimation and detection model. Neurolmage 34, 195-203.

Makeig, S., Debener, S., Onton, J., Delorme, A., 2004. Mining event-related brain dynamics. Trends Cogn. Sci. 8, 204-210.

Mantini, D., Perrucci, M.G., Del Gratta, C., Romani, G.L., Corbetta, M., 2007. Electrophysiological signatures of resting state networks in the human brain. Proc. Natl. Acad. Sci. U. S. A. 104, 13170-13175.

Marks, D.F., Isaac, A.R., 1995. Topographical distribution of EEG activity accompanying visual and motor imagery in vivid and non-vivid imagers. Br. J. Psychol. 86 (Pt 2), 271-282.

Mellet, E., Tzourio, N., Crivello, F., Joliot, M., Denis, M., Mazoyer, B., 1996. Functional anatomy of spatial mental imagery generated from verbal instructions. J. Neurosci. 16, 6504-6512.

Mellet, E., Petit, L., Mazoyer, B., Denis, M., Tzourio, N., 1998. Reopening the mental imagery debate: lessons from functional anatomy. Neurolmage 8, 129-139.

Mellet, E., Tzourio-Mazoyer, N., Bricogne, S., Mazoyer, B., Kosslyn, S.M., Denis, M., 2000. Functional anatomy of high-resolution visual mental imagery. J. Cogn. Neurosci. 12, 98-109.

Mitchell, K.J., Johnson, M.K., Raye, C.L., D'Esposito, M., 2000. fMRI evidence of age-related hippocampal dysfunction in feature binding in working memory. Brain Res. Cogn. Brain Res. 10, 197-206.
Munk, M.H., Linden, D.E., Muckli, L., Lanfermann, H., Zanella, F.E., Singer, W., Goebel, R. 2002. Distributed cortical systems in visual short-term memory revealed by eventrelated functional magnetic resonance imaging. Cereb. Cortex 12, 866-876.

Neuper, C., Pfurtscheller, G., 2001. Event-related dynamics of cortical rhythms: frequency-specific features and functional correlates. Int. J. Psychophysiol. 43, 41-58.

Nikolaev, A.R., Anokhin, A.P., 1998. EEG frequency ranges during perception and mental rotation of two- and three-dimensional objects. Neurosci. Behav. Physiol. 28, 670-677.

O'Craven, K.M., Kanwisher, N., 2000. Mental imagery of faces and places activates corresponding stiimulus-specific brain regions. J. Cogn. Neurosci. 12, 1013-1023.

Onton, J., Delorme, A., Makeig, S., 2005. Frontal midline EEG dynamics during working memory. NeuroImage 27, 341-356.

Petsche, H., Lacroix, D., Lindner, K., Rappelsberger, P., Schmidt-Henrich, E., 1992. Thinking with images or thinking with language: a pilot EEG probability mapping study. Int. J. Psychophysiol. 12, 31-39.

Petsche, H., Kaplan, S., von Stein, A., Filz, O., 1997. The possible meaning of the upper and lower alpha frequency ranges for cognitive and creative tasks. Int. J. Psychophysiol. 26, 77-97.

Podzebenko, K., Egan, G.F., Watson, J.D., 2002. Widespread dorsal stream activation during a parametric mental rotation task, revealed with functional magnetic resonance imaging NeuroImage 15, 547-558.

Prabhakaran, V., Narayanan, K., Zhao, Z., Gabrieli, J.D., 2000. Integration of diverse information in working memory within the frontal lobe. Nat. Neurosci. 3 85-90.

Prince, S.E., Dennis, N.A., Cabeza, R., 2009. Encoding and retrieving faces and places: distinguishing process- and stimulus-specific differences in brain activity. Neuropsychologia 47, 2282-2289.

Richter, W., Ugurbil, K., Georgopoulos, A., Kim, S.G., 1997. Time-resolved fMRI of mental rotation. Neuroreport 8, 3697-3702.

Richter, W., Somorjai, R., Summers, R., Jarmasz, M., Menon, R.S., Gati, J.S., Georgopoulos, A.P., Tegeler, C., Ugurbil, K., Kim, S.G., 2000. Motor area activity during mental rotation studied by time-resolved single-trial fMRI. J. Cogn. Neurosci. 12, 310-320.

Riesenhuber, M., Poggio, T., 2000. Models of object recognition. Nat. Neurosci. 1199-1204 (Suppl).

Roebroeck, A., Formisano, E., Goebel, R., 2005. Mapping directed influence over the brain using Granger causality and fMRI. NeuroImage 25, 230-242.

Rugg, M.D., Venables, P.H., 1980. EEG correlates of the acquisition of high- and lowimagery words. Neurosci. Lett. 16, 67-70.

Sack, A.T., Sperling, J.M., Prvulovic, D., Formisano, E., Goebel, R., Di Salle, F., Dierks, T., Linden, D.E., 2002. Tracking the mind's image in the brain II: transcranial magnetic stimulation reveals parietal asymmetry in visuospatial imagery. Neuron 35, 195-204.

Sack, A.T., Camprodon, J.A., Pascual-Leone, A., Goebel, R., 2005. The dynamics of interhemispheric compensatory processes in mental imagery. Science 308, 702-704.

Serences, J.T., 2004. A comparison of methods for characterizing the event-related BOLD timeseries in rapid fMRI. NeuroImage 21, 1690-1700.

Swadlow, H.A., 2003. Fast-spike interneurons and feedforward inhibition in awake sensory neocortex. Cereb. Cortex 13, 25-32.

Tagaris, G.A., Kim, S.G., Strupp, J.P., Andersen, P., Ugurbil, K., Georgopoulos, A.P., 1996 Quantitative relations between parietal activation and performance in mental rotation. Neuroreport 7, 773-776.

Talairach, J., Tournoux, P., 1988. Co-planar Stereotaxic Atlas of the Human Brain: 3Dimenstional Proportional System - An Approach to Cerebral Imaging. Thieme Medical Publishers, New York.

Talati, A., Hirsch, J., 2005. Functional specialization within the medial frontal gyrus for perceptual go/no-go decisions based on "what," "when," and "where" related information: an fMRI study. J. Cogn. Neurosci. 17, 981-993.

Tallon-Baudry, C., Bertrand, O., Peronnet, F., Pernier, J., 1998. Induced gamma-band activity during the delay of a visual short-term memory task in humans. J. Neurosci. $18,4244-4254$

Tallon-Baudry, C., Bertrand, O., Fischer, C., 2001. Oscillatory synchrony between human extrastriate areas during visual short-term memory maintenance. J. Neurosci. 21, RC177.

Trojano, L., Grossi, D., Linden, D.E., Formisano, E., Hacker, H., Zanella, F.E., Goebel, R., Di Salle, F., 2000. Matching two imagined clocks: the functional anatomy of spatial analysis in the absence of visual stimulation. Cereb. Cortex 10, 473-481.

Trojano, L., Grossi, D., Linden, D.E., Formisano, E., Goebel, R., Cirillo, S., Elefante, R., Di Salle, F., 2002. Coordinate and categorical judgements in spatial imagery. An fMRI study. Neuropsychologia 40, 1666-1674.

Tulving, E., Markowitsch, H.J., Craik, F.E., Habib, R., Houle, S., 1996. Novelty and familiarity activations in PET studies of memory encoding and retrieval. Cereb. Cortex $6,71-79$.

Ungerleider, L.G., Haxby, J.V., 1994. 'What' and 'where' in the human brain. Curr. Opin. Neurobiol. 4, 157-165

Valdes-Sosa, P.A., Roebroeck, A., Daunizeau, J., Friston, K., 2011. Effective connectivity: influence, causality and biophysical modeling. Neurolmage 58, 339-361.

Ward, B.D., 1998. Deconvolution Analysis of FMRI Time Series Data. http://afni.nimh. nih.gov/pub/dist/doc/manual/Deconvolvem.pdf 